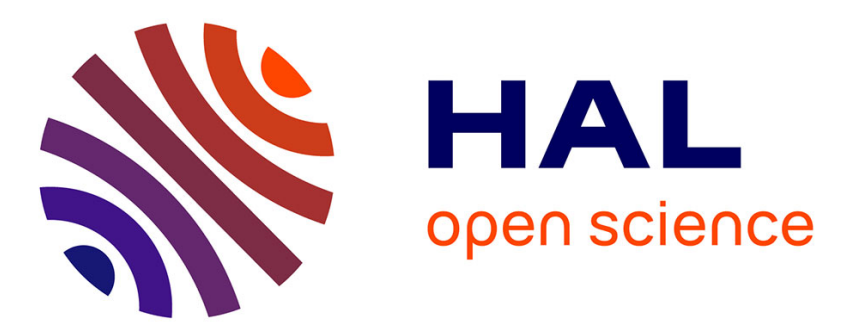

\title{
Assessing surface DEM and roughness with a 3D-printed gravel bed
}

\author{
Stéphane Bertin, Heide Friedrich, Patrice Delmas, Edwin Chan, Georgy \\ Gimel'Farb
}

\section{- To cite this version:}

Stéphane Bertin, Heide Friedrich, Patrice Delmas, Edwin Chan, Georgy Gimel'Farb. Assessing surface DEM and roughness with a 3D-printed gravel bed. RiverFlow 2014, Sep 2014, Lausanne, Switzerland. hal-03470826

\section{HAL Id: hal-03470826 \\ https://hal.science/hal-03470826}

Submitted on 8 Dec 2021

HAL is a multi-disciplinary open access archive for the deposit and dissemination of scientific research documents, whether they are published or not. The documents may come from teaching and research institutions in France or abroad, or from public or private research centers.
L'archive ouverte pluridisciplinaire HAL, est destinée au dépôt et à la diffusion de documents scientifiques de niveau recherche, publiés ou non, émanant des établissements d'enseignement et de recherche français ou étrangers, des laboratoires publics ou privés. 


\title{
Assessing surface DEM and roughness with a 3D-printed gravel bed
}

\author{
S. Bertin \& H. Friedrich \\ Department of Civil and Environmental Engineering, The University of Auckland, Auckland, New Zealand \\ P. Delmas \& E. Chan \& G. Gimel'farb \\ Department of Computer Science, The University of Auckland, Auckland, New Zealand
}

\begin{abstract}
High-resolution digital elevation models (DEMs) of gravel riverbeds are common tools for studying surface roughness. However, a necessary step in these studies, the DEM quality assessment, remains challenging. To highlight its importance, we review present surface roughness characterization methods for gravel beds and propose to build a realistic gravel-bed model with known elevations using modern 3D printing technology. The model is placed in a laboratory flume and measured through-air with digital stereo photogrammetry. To evaluate the measurement performance, the measured and "truth" models are mutually aligned and compared point-by-point. Our experiments showed high accuracy, namely, the mean unsigned error (MUE) of $0.43-\mathrm{mm}$ and standard deviation of error (SDE) of $0.62-\mathrm{mm}$ in the viewed area of $296 \times 184-$ $\mathrm{mm}^{2}$. In terms of external reliability, small discrepancies were observed between the measured and true statistical roughness parameters. DEM quality assessment with a 3D printed model will be useful for setting up the optimum strategy for gravel-bed DEM collection, both in air and through-water, in future.
\end{abstract}

\section{SURFACE ROUGHNESS CHARACTERISATION REVIEW}

Recent advances in remote sensing of gravel riverbed morphology have allowed for determining roughness parameters directly from the riverbed geometry (Aberle and Nikora, 2006, Butler et al., 2001, Hodge et al., 2009, Mao et al., 2011, Nikora et al., 1998). Using the random-field approach, the riverbed is measured as a spatiotemporal function $z(x, y, t)$, where $z$ is the bed elevation over the time $t$ above a plane, defined by the two orthogonal $x$ and $y$ directions. For a fixed time instant, the riverbed surface can be represented as a 2.5D DEM, where each surface point is represented by one elevation.

The hydraulic roughness, a traditional parameter related to a simple percentile of the grain size distribution (GSD) of the sediment constituting the bed (e.g. $k_{s}=3.5 D_{84}$ ), has morphed into a complex function, able to characterise the morphology of the three dimensional surface at different scales (Butler et al., 2001, Nikora et al., 1998, Robert, 1988). The standard deviation of bed elevations, $\sigma_{z}$, has been used to describe the "sand-equivalent" vertical roughness length, $k_{s}$, in situations where previous methods for roughness parameterisation failed (Smart et al., 2002). Influenced by theoretical developments on the dynamic behaviour of sand bedforms, the semivariogram approach, which analyses at different spatial lags the elevation correlations between DEM points, has allowed the characterisation of both the longitudinal and transverse roughness lengths and the geometric scales inherent to a water-worked gravel-bed surface, such as grain and bedform scales (Nikora et al., 1998, Robert, 1988, Butler et al., 2001). A 2D semivariogram, also called generalised second-order structure function, is calculated with the following relationship, defined in Nikora et al. (1998) in discrete form as:

$$
\begin{aligned}
& D_{G 2}(\Delta x, \Delta y)=\frac{1}{(N-n)(M-m)} \\
& \sum_{i=0}^{N-n M-m} \sum_{j=0}^{M}\left\{\left|z\left(x_{i}+n \delta x, y_{j}+m \delta y\right)-z\left(x_{i}, y_{j}\right)\right|\right\}^{2}
\end{aligned}
$$

where, $\Delta x=n \delta x$ and $\Delta y=m \delta y ; \delta x$ and $\delta y$ are sampling intervals in the longitudinal and transverse directions respectively; $n=1,2,3, \ldots N$ and $m=1,2,3, \ldots M . N$ and $M$ are the number of samples in the same two directions. The relationship in Eq. (1) can be used to represent the 1D semivariograms (i.e. along a single direction), as well as contour plots of the 2D semivariograms. At small spatial lags, in the "scaling region", the 1D semivariograms can be fitted by a power function of the form $D(\Delta x) \sim \Delta x^{2 H x}$ and $D(\Delta y) \sim \Delta y^{2 H y}$. Butler et al. (2001) and Robert (1988) showed that when plotted in log-log scale, the use of a power function allows the determination of the directional Hurst exponents $H_{x}$ and $H_{y}$, representing a basic method to estimate the fractal dimen- 
sion of series of data along the downstream and transverse directions, respectively. The scaling region also provides information about the horizontal roughness indices $\Delta x_{0}$ and $\Delta y_{0}$, which can be determined from the slope breakpoint, located at the intersection between the tangent to the scaling region slope and the saturation level asymptote, in both $x$ and $y$ directions.

Other surface properties, like the inclination of sediment particles, can be estimated directly from a DEM. The inclination index, developed by Smart et al. (2004), later extended by Millane et al. (2006), measures the inclination of gravels at different spatial lags. The inclination index $(I)$ for a certain direction is defined by the relationship:

$I(d)=\frac{N_{+}(d)-N_{-}(d)}{N}$

where $N_{+}$and $N_{-}$are the number of positive and negative slopes in the direction, respectively, for a distance $d$ between points. In the numerator, slopes smaller than a threshold have been removed to eliminate the influence of small gradients that cannot be considered reliable (Qin et al., 2012). The denominator $N$ is the total number of measured slopes.

\section{DEM QUALITY ASSESSMENT}

The above presented development of a traditional single component roughness value to complex $3 \mathrm{D}$ pattern descriptors for gravel beds, based on everimproving DEM data, highlights the need for studies on DEM quality assessment. Statistical roughness characterisation using a DEM, or using a DEM in high-resolution CFD, requires a high confidence in the measured elevations, since errors of small magnitude can propagate and seriously affect the reliability of the findings (Lane et al., 2005, James et al., 2007, Hodge et al., 2009). DEMs thus generally undertake a quality assessment to ensure accuracy and precision in the measured elevations and reliability in the extracted parameters. Various approaches have been implemented in practice. The most common is to dispose check points on the surface to measure. Their position is determined independently and compared with the measurements (Bouratsis et al., 2013, Butler et al., 1998, Carbonneau et al., 2003, Lane et al., 2000, Lane et al., 2005). Limitations to this approach arise from the density and repartition of check points. When the number of check points is small compared to the number of DEM points, derived measures of data quality may not be representative of the DEM collection process (Butler et al., 2002, Lane et al., 2000).

An improvement can be made by dually measuring the same surface, allowing DEM differentiation over a high number of homogeneously distributed points (Chandler et al., 2001). However, this method requires the availability of a concurrent measuring device, able to measure with high-accuracy and resolution. In addition, longer setup and processing time is needed, as a second DEM must be obtained, edited and blunders removed before comparison. Therefore the applicability of this method is seldom feasible.

To negotiate those challenges, another approach, measuring objects of known size, seems to be the most suited for applications in hydraulic engineering. Examples can be found already in the work of (Bouratsis et al., 2013, Hodge et al., 2009, Wang et al., 2009, Chandler et al., 2005). As those studies show, the main difficulty here is that data are assessed with an object that is not representative of the surface of interest (Wang et al., 2009).

\section{PAPER OVERVIEW}

This paper presents a novel method for DEM quality assessment. A surface, realistic of a water-worked gravel bed, is prepared with a 3D printer. The model has known elevations. It can be placed in various environments and recorded with the measuring device chosen for the experiment. In this study, the performance of digital stereo photogrammetry is evaluated. A strategy to precisely align the measured DEM with the "truth" DEM is outlined, allowing obtaining reliable point-by-point differentiation and accuracy statistics. In terms of external reliability, statistical roughness parameters, derived from the measured DEM, were compared with the "true" values calculated from the truth DEM. This paper concludes with a discussion on the pros and cons of the proposed method and recommendations for future work.

\section{METHODOLOGY}

\subsection{Measurement environment}

A 19-m long, 0.45-m wide and 0.5-m deep hydraulic flume is used for the purpose of experiments on grain-scale gravel-bed monitoring with stereo photogrammetry.

A screeded gravel bed is prepared in a one meter long, full-width sediment recess, and situated 14-m downstream from the inlet. The initially flat gravel bed is water-worked and the evolving bed topography is recorded through-air after the flume is drained. Two cameras are rigidly attached horizontally above the test section, using a gantry-mounted sliding system on a rail. Nikon D5100s, consumergrade DSLR cameras, with 16.2-MP (4928 x 3264 pixel), and Nikkor 20-mm fixed-focal lenses, comprise the stereo-photogrammetric setup. To minimise the issue of gravel protruding and shadowing the 
surrounding, which is a major source of photogrammetric errors (Chandler et al., 2001), vertical imagery is recorded.

The lighting environment is made of four one meter long neon lights $(58 \mathrm{~W}$ with carbon dioxide to create 'cool daylight' colour). Two lights are placed at the horizontal on each side of the flume, one above the other. White Plexiglas diffusing sheets are placed against the flume transparent sidewalls, to make the lighting more homogenous.

\subsection{General photogrammetric workflow}

The photogrammetric process steps employed to reconstruct a DEM from two overlapping images (stereo pair) are summarised in Table I. A detailed description of the photogrammetric workflow is presented in Bertin et al. (2013).

\subsection{Preparation of the realistic $3 D$ printed gravel bed}

The motivation behind this work is the presumed ability to prepare a surface model of known dimensions, which mimics the real topography of gravel beds simulated in our laboratory experiments. Recent advances in 3D printing have been substantial, allowing detailed replication of the topography of a water-worked gravel bed.

Initially, a standard sediment mixture $\left(D_{50}=7.3\right.$ $\mathrm{mm}$, minimum size of 0.7-mm, maximum size of 65$\mathrm{mm}$ and $\left.\left(D_{84} / D_{16}\right)^{1 / 2}=2.98\right)$ was used to create a flat gravel bed in the hydraulic flume. A constant flow rate of $60-1 / \mathrm{s}$ and constant water depth of $200-\mathrm{mm}$ was applied, until no sediment movement was observed. The grain size distribution of the armoured surface was estimated using the image-based technique developed in Detert and Weitbrecht (2012), called BASEGRAIN ${ }^{\circledR}$, providing $D_{50}=13-\mathrm{mm}$ and $\left(D_{84} / D_{16}\right)^{1 / 2}=3.2$.

Digital stereo photogrammetry available allows for the best compromise between measurement resolution and theoretical accuracy (Bertin and Friedrich, 2014). Therefore it was adopted to produce a $2.5 \mathrm{D}$ DEM of the water-worked surface with pixel size of $0.18-\mathrm{mm}$ and optimal vertical precision of $0.35-\mathrm{mm}$ in the object space. The DEM was cropped to a size of 296-mm along the flow direction and 184-mm transverse. This was the largest dimension the 3D printer could produce. The sampling distance in the DEM, 0.25-mm, was chosen small enough to allow evaluating the effects of changing the DEM grid size on DEM quality. Additional processing was done to facilitate the assessment of future data. The corners of the model were made flat over 5-mm squares, elevations were normalised around a zero mean and stored in the "truth" elevation matrix (of data size $1185 \times$ 737). The 2.5D DEM was rendered as a hollow object by replicating the surface 5-mm below. The resulting 3D DEM (Fig. 1) was finally transformed in a stereo lithography (.stl) file and sent to the $3 \mathrm{D}$ printer.

A ProJet ${ }^{\circledR} 3500$ HDPlus from 3DSYSTEMS was employed for the manufacturing. Successive layers of material, described as a transparent plastic, were laid down to produce in 15 hours the shape of the model with a manufacturer-specified accuracy range of [0.033-0.066-mm].

Similar to Chandler et al. (2005), surface finishing was applied. In our case, the surface of the 3D printed model was finished to improve the initially low stereo matching capabilities afforded by the 3D model surface by $(i)$ painting the model in matte black to make the object opaque; and (ii) adding very fine sand $\left(D_{50}<0.2-\mathrm{mm}\right)$ to create some real texture (Fig. 1).

TABLE I. Essential steps in the workflow used for collecting and processing photogrammetric data.

\begin{tabular}{|c|c|c|c|}
\hline & & Input & Output \\
\hline \multirow[t]{3}{*}{$\begin{array}{l}\text { Setup } \\
\text { preparation }\end{array}$} & 1. Design setup & $\begin{array}{l}\text { - Measurement window size (even- } \\
\text { tually margin size) }\end{array}$ & $\begin{array}{l}\text { - Optimum camera-to-object } \\
\text { distance }\end{array}$ \\
\hline & & $\begin{array}{l}\text { - Camera geometry (sensor dimen- } \\
\text { sion, focal length) } \\
\text { - Camera baseline }\end{array}$ & $\begin{array}{l}\text { - Measurement specifications } \\
\text { (resolution, theoretical ac- } \\
\text { curacy, overlap, ...) }\end{array}$ \\
\hline & $\begin{array}{l}\text { 2. Mechanical alignment } \\
\text { 3. Manual focusing } \\
\text { 4. Exposure setting }\end{array}$ & & \\
\hline Data & 1. Calibration images & & \\
\hline \multirow{5}{*}{$\begin{array}{l}\text { Data } \\
\text { processing }\end{array}$} & $\begin{array}{l}\text { 2. Images of surface to measure } \\
\text { 1. Camera and setup calibration }\end{array}$ & - Calibration images & - Calibration parameters \\
\hline & 2. Epipolar rectification $*$ & $\begin{array}{ll}\text { - } & \text { Calibration parameters } \\
\text { - } & \text { Stereo pair of surface to measure }\end{array}$ & $\begin{array}{l}\text { - Rectified stereo pair of sur- } \\
\text { face to measure }\end{array}$ \\
\hline & 3. Stereo-matching & $\begin{array}{l}\text { - Rectified stereo pair of surface to } \\
\text { measure }\end{array}$ & $\begin{array}{ll} & \text { Depth map } \\
\text { - } & \text { Ortho photograph }\end{array}$ \\
\hline & 4. Point cloud extraction & $\begin{array}{ll}- & \text { Depth map } \\
\text { - } & \text { Calibration results }\end{array}$ & $\begin{array}{l}\text { - Point cloud text file with co- } \\
\text { ordinates of all pixels }\end{array}$ \\
\hline & 5. DEM reconstruction & - Point cloud & - DEM on regular grid \\
\hline
\end{tabular}

* In epipolar geometry, corresponding pixels in a stereo pair are on a same scan-line (i.e. same vertical image coordinate) 


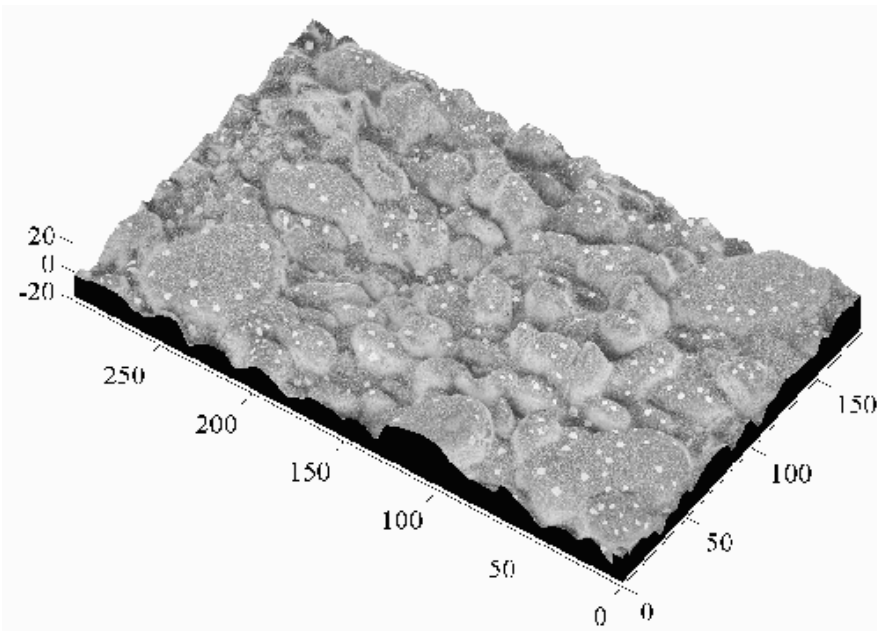

Figure 1. The "truth" gravel-bed DEM, as sent to the 3D printer, draped with a grey-scale ortho-image of the model after surface finishing. The 3D printed model size is $296 \times 184-\mathrm{mm}^{2}$, and check points are sampled every $0.25-\mathrm{mm}$ in both directions. Therefore, the total number of check points is 873,345 .

The surface coating impact on the assessment was neglected, as the addition of sand can be approximated by a uniform shift in bed elevation, which is eliminated when the measured DEM is vertically aligned with the truth DEM (see Section 'Assessment of DEM quality using the 3D printed gravel bed' for explanations on the alignment process).

\section{EXPERIMENTS}

\subsection{Implementation of the measurement technique}

This Section presents the particular photogrammetric setup that was evaluated with the 3D printed gravel bed in this study. The setup was designed to comply with a desired measurement window of size 450-mm in the flow direction and 400-mm transverse, which is common practice in our laboratory experiments (Bertin et al., 2013). A 50-mm margin around the measurement window was accounted for and cropped before analysis. Table II summarises the resulting measurement specifications.

Image acquisition was done with JPEG (1:4) fine format, f/10 aperture, ISO 200 and 1/15-s exposure time. 30 stereo pairs of a calibration checkerboard covering the whole cameras' common field of view $(\mathrm{CFOV})$ and at distances close to the camera-toobject distance were recorded for camera and setup calibration (Table I). Finally, a stereo pair of the 3D printed model was recorded.

After processing of the photogrammetric data, a DEM of the 3D printed gravel bed (known as the "measured" DEM) was reconstructed on a grid with spacing $0.25-\mathrm{mm}$, the same as the distance between check points in the $3 \mathrm{D}$ printed model. It is noted that the minimum grid size possible was $0.15-\mathrm{mm}$ (Table II). Median filtering, a built-in function of the SDPS (Bertin et al., 2013) and a common practice to re- move outliers in surveying (Carbonneau et al., 2003), was utilised on the map of bed elevations with the default parameters. Each pixel elevation was replaced by the median value calculated over two orthogonal lines ( 3 pixels long along $x$ and 11 pixels long along $y$ ) crossing at the pixel location.

\subsection{Assessment of DEM quality using the $3 D$ printed gravel bed}

To allow measurement quality to be assessed, the measured DEM of the 3D printed gravel bed needs to align the truth DEM. Data alignment has to be performed separately of the DEM reconstruction process, since the measured DEM of the 3D printed model does initially not have a common coordinate system with the truth DEM. The data was aligned as follows: (i) the 3D printed model is placed horizontally in the hydraulic flume, at the location where the gravel bed is normally recorded, with its long axis parallel to the cameras' horizontal axis; (ii) horizontal alignment is performed with a search algorithm to find the region where the 3D printed model is represented in the measured DEM (Fig. 2, left); (iii) vertical alignment makes use of surface detrending algorithms to remove any tilt between the measured and truth DEM (Fig. 2, middle and right). Finally, the two DEMs (Fig. 3) are differentiated point-bypoint (Fig. 4), to provide statistical measures of accuracy and precision (Table III).

The external reliability of the measurements was assessed by comparing the values of statistical roughness parameters extracted from the measured DEM with the "true" values calculated directly from the truth DEM. Before the computation of grainscale roughness parameters, both measured and truth DEMs were detrended, following the same approach, to remove any significant feature that could conceal the grain-scale structure.

Using the criteria of Andreas and Trevino (1997), biquadratic detrending was found significant and reduced the variance of the data the most. Therefore, bi-quadratic trends were fitted in a least-square sense and removed from the DEMs.

TABLE II. Summary of the photogrammetric setup designed for the test. All values were theoretically determined using the standard perspective-projection formulae and the rounded camera-to-object distance. Actual values may deviate because of the difficulty in practice to accurately set the cameras 'flyingheight' and cameras baseline.

\begin{tabular}{ll}
\hline Rounded camera-to-object distance $(\mathrm{mm})$ & 636 \\
CFoV $(\mathrm{mm})$ & $500 \times 498$ \\
Baseline $(\mathrm{mm})$ & 250 \\
Overlap $(\%)$ & 67 \\
Sampling distance $(\mathrm{mm}) /$ resolution $\left(\mathrm{pixel} / \mathrm{mm}^{-2}\right)$ & $0 \cdot 15 / 43$ \\
Theoretical vertical precision $(\mathrm{mm})$ & $0 \cdot 39$ \\
Number of pixels in the $450 \times 400-\mathrm{mm}$ measure- & $\simeq 7,800,000$ \\
ment window (-) &
\end{tabular}



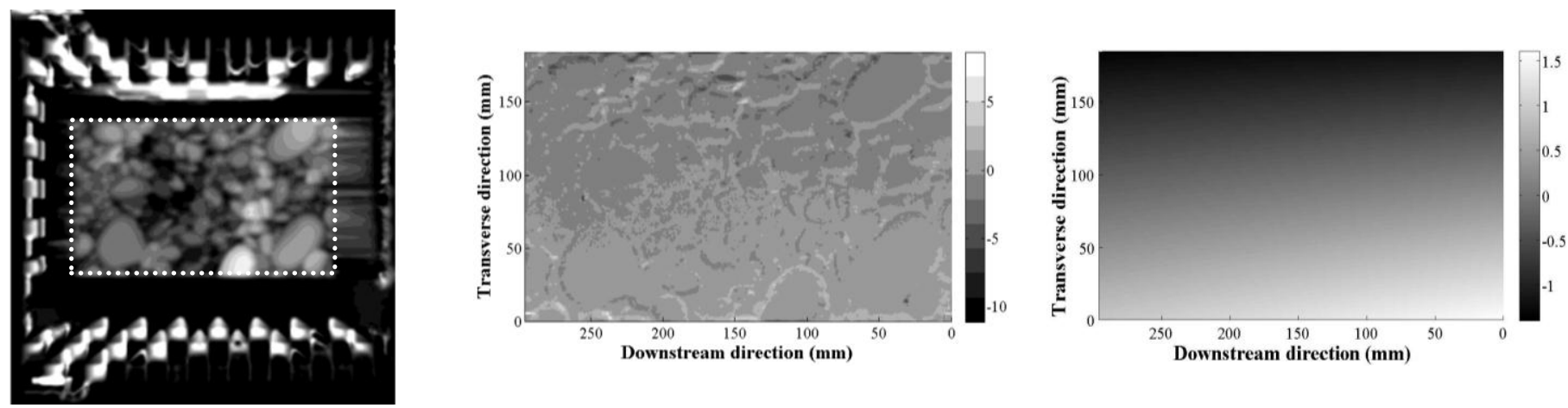

Figure 2. The DEM alignment process. (Left) During horizontal alignment, the region where the 3D printed model is represented in the measured DEM is determined (the surface enclosed in the white dotted line). Before vertical alignment (middle), a tilt between the measured and the truth DEM is evident in the DEM of difference (DoD). (Right) This image presents the bilinear trend characterizing the misalignment. This trend was removed from the measured DEM before assessment. Elevations are in millimetre.

\section{RESULTS}

\subsection{Assessment of DEM accuracy}

Figure 3 allows a qualitative comparison of the measured DEM (top) with the truth DEM (bottom). Visually, the whole surface of the 3D printed gravel bed is correctly represented in the measured DEM, with no obvious errors. A possible observation, however, is a surface that appears lightly blurry compared with the representation of the truth DEM.

Figure 4 shows the DoD (absolute differences are represented for clarity) obtained from the differentiation of the measured DEM after horizontal and vertical alignment with the truth DEM, over the full area of the 3D printed model. The DoD shows that surface errors are located at the grains' edges and gaps between grains. This observation relates well with findings obtained by Chandler et al. (2001), where stereo-matching outliers were found near deep crevices between grains at the surface of a gravel bed. The reason is that occluded regions in the imagery, where pixels are replaced by values interpolated from neighbouring data, based on the assumption of a continuous surface, are smoothed in the DEMs and introduce surface errors. The light blurriness (Fig. 3, top) may be the consequence of the interpolation of points in occluded regions. Another explanation relates to the use of median filtering, which is efficient at removing noise in a DEM, but adversely affects edges.

Table III shows statistics on the surface error, obtained from the comparison of the elevations contained in the measured DEM with the "true" elevations, over all check points $(n=873,345)$. Whilst a mean error (ME) of $0.04-\mathrm{mm}$ suggests that the data alignment procedure was effective, the evaluation of the average surface error, represented by a mean unsigned error (MUE) of $0.43-\mathrm{mm}$, is needed to characterise the DEM accuracy. The global surface precision is characterised by SDE of $0.62-\mathrm{mm}(\simeq 5 \%$ of surface $\left.D_{50}\right)$. Most DEM points $(90 \%)$ are within \pm 1 $\mathrm{mm}$ of check points, and $0.5 \%$ of DEM points exhibit errors above 3-mm.

\subsection{Assessment of DEM external reliability}

As noted previously, both the measured DEM and the truth DEM were bi-quadraticly detrended, estimating the trend of a least-square best fit. The trends, removed from the DEMs before computation of statistical roughness parameters, were compared and presented a mean unsigned difference of 0.026 $\mathrm{mm}$ and a standard deviation of difference of 0.035 $\mathrm{mm}$.

Table IV reports the values of the statistical roughness parameters calculated from the measured DEM and the "true" values extracted from the truth DEM, after detrending. The first four parameters (the standard deviation of bed elevations $\sigma_{Z}$, the range of elevations $\Delta Z$, skewness $S_{k}$ and kurtosis $K_{u}$ ) characterise the distribution and shape of surface elevations. The measured DEM has a reduced standard deviation and range of surface elevations. Although, the reduction in $\sigma_{Z}$ and $\Delta Z$ is small (relative reduction of $2.2 \%$ and $3.0 \%$, respectively), it

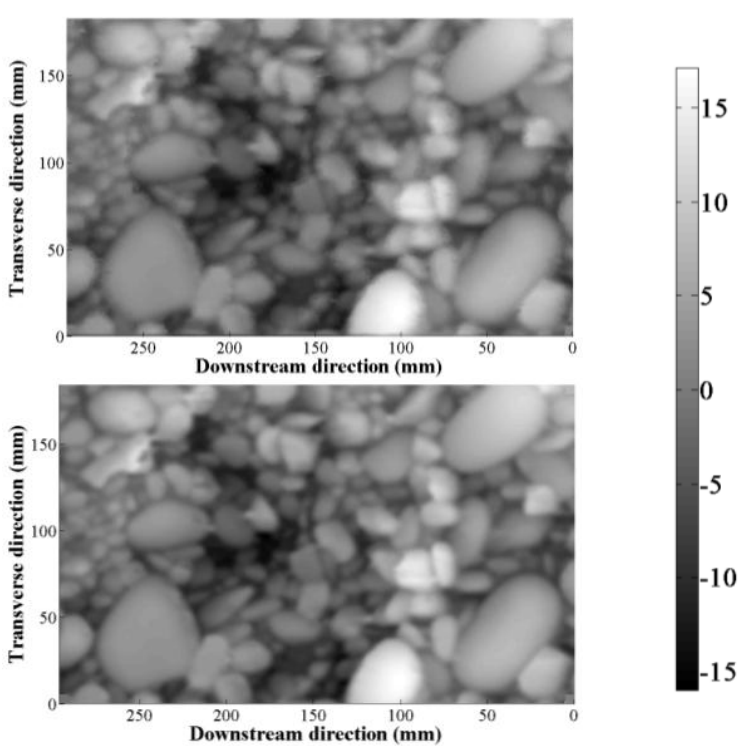

Figure 3. (top) Measured DEM of the 3D printed model collected with $0.25-\mathrm{mm}$ sampling distance, horizontally and vertically aligned with the ground truth; (bottom) truth DEM. The same colour representation, with elevation-scale in millimetre, is used for both DEMs. 


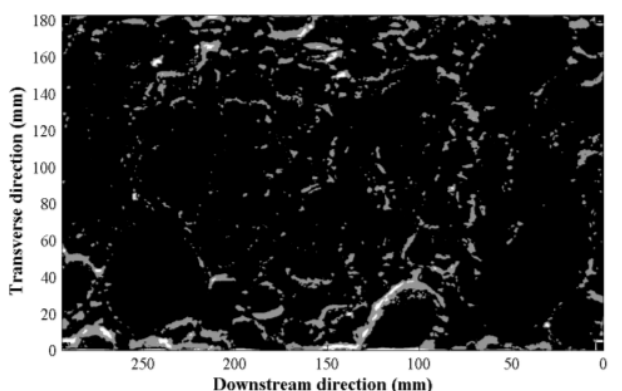

Figure 4. DEM of absolute difference obtained after point-bypoint differentiation of the measured DEM, after alignment, with the truth DEM.
TABLE IV. Statistical roughness parameters, extracted from the measured DEM and the truth DEM ("true" values) of the 3D printed gravel bed.

\begin{tabular}{|c|c|c|c|}
\hline Parameters & $\begin{array}{l}\text { Measured } \\
\text { values }\end{array}$ & $\begin{array}{l}\text { True } \\
\text { values }\end{array}$ & $\begin{array}{l}\text { Relative dif- } \\
\text { ference }(\%)\end{array}$ \\
\hline$\sigma_{Z}(\mathrm{~mm})$ & 4.83 & 4.94 & -2.2 \\
\hline$\Delta Z(\mathrm{~mm})$ & 30.01 & 30.95 & -3.0 \\
\hline$S_{k}$ & 0.17 & 0.10 & +41 \\
\hline$K_{u}$ & 3.12 & 3.03 & +2.9 \\
\hline$H_{x}$ & 0.81 & 0.85 & -4.7 \\
\hline$H_{y}$ & 0.81 & 0.86 & -5.8 \\
\hline$\Delta x_{0}(\mathrm{~mm})$ & 10.92 & 10.22 & +6.4 \\
\hline$\Delta y_{0}(\mathrm{~mm})$ & 9.53 & 9.39 & +1.5 \\
\hline
\end{tabular}

Figure 6 presents the inclination indices $\left(I_{x}\right.$ and ME (mm)

MUE (mm)

SDE $(\mathrm{mm})$

Maximum absolute error $(\mathrm{mm})$

DEM points within \pm 0.5 -mm with check points $(\%)$

DEM points within $\pm 1-\mathrm{mm}$ with check points $(\%)$

DEM points within \pm 3 -mm with check points $(\%)$

suggests measurements were incorrect at some locations. In accordance with Figure 4, a larger skewness for the measured DEM (0.17 instead of 0.10 for the truth DEM) is attributed to a degraded measurement performance in regions of negative elevations, thus at the interstices between particles.

The other parameters (the Hurst exponents $H_{x}$, and $H_{y}$, and the horizontal roughness lengths $\Delta x_{0}$ and $\Delta y_{0}$, where $x$ represents the flow direction and $y$ the direction transverse) are based upon the semivariogram analysis and vary more notably, with a relative variation between measured and reference values of $4.7 \%, 5.8 \%, 6.4 \%$ and $1.5 \%$, respectively.

Although Figure 5 shows that the 2D semivariograms computed from the measured DEM and the truth DEM, after detrending, are almost identical, analysis of the 1D properties resulted in observable differences (Table IV). The larger roughness lengths (and smaller Hurst exponents) of the measured DEM may relate to median filtering and the smoothing of occluded areas. The smoothing of the reconstructed surface, as seen by the blurriness in Figure 3 (top), results in a slight reduction in the size of the gaps between particles, and thus areas occupied by the particles are magnified. Although this could not be proved quantitatively, Figures 3-4 provide visual hints for this statement.

The effect of median filtering on semivariogramderived parameters was further evaluated. Another DEM was collected without the use of median filtering and compared with the truth DEM. This resulted in deteriorated DEM quality, as shown by MUE = $0.50-\mathrm{mm}, \mathrm{SDE}=0.75-\mathrm{mm}, 7.7 \%$ difference in $\Delta x_{0}$ and $2.9 \%$ difference in $\Delta y_{0}$, therefore suggesting that median filtering is efficient at removing outliers in DEMs, improving both DEM accuracy and external reliability. $\left.I_{y}\right)$ for both the measured DEM and the truth DEM. There is a good agreement in inclination index along the flow direction, but the inclination indices calculated in the transverse direction divert from each other, especially at small spatial lags. Thus, the measured DEM reflects predominance of positive slopes in the direction of the flow, which is characteristic of the imbrication of gravel with waterworking (Millane et al., 2006, Qin et al., 2012, Smart et al., 2004). In cross-flow direction, however, the slight offset in measured and truth DEM inclination indices fluctuates around zero for small spatial lags.

In light of the work of Millane et al (2006), the validity of the assessment based on the inclination index can be questioned because of the very small values observed. Millane et al. (2006) suggested that suitable data for the use of the inclination index should present a clear drop in the maximum

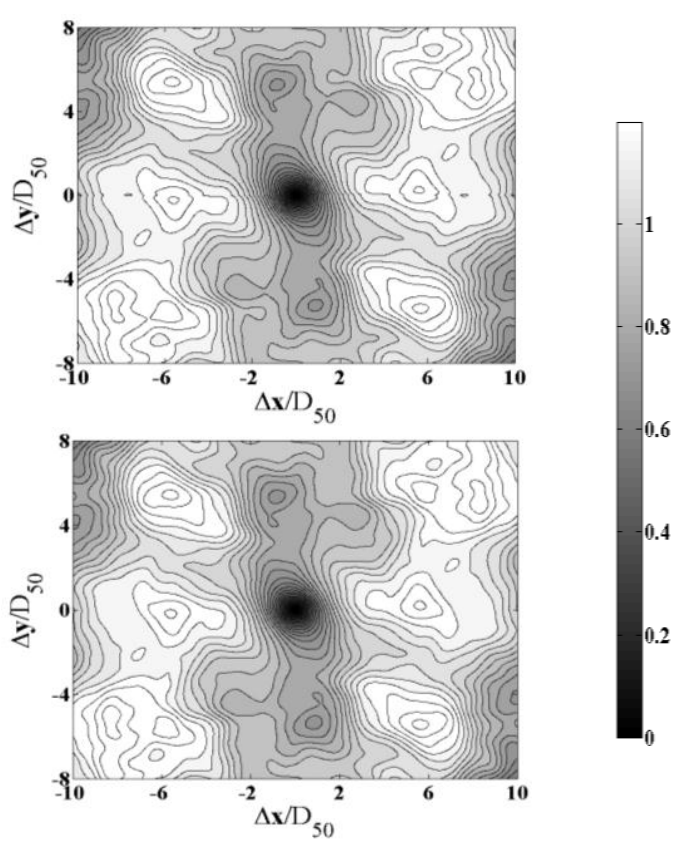

Figure 5. 2D semivariogram versus distance lags normalised by the median sediment size, calculated over (top) the measured DEM; and (bottom) the truth DEM. The same colour representation is applied to the two semivariograms. The maximum lag was chosen to encompass all sediment size found on the DEM surface. 


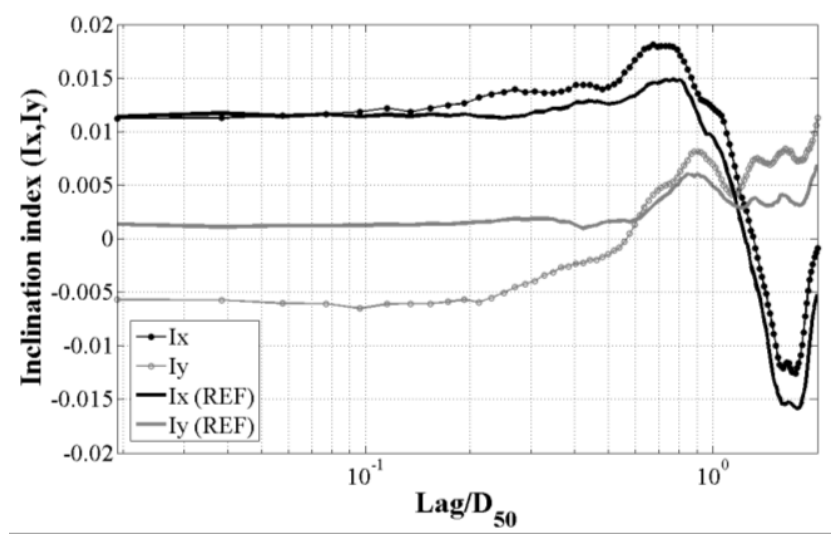

Figure 6. Inclinations indices versus the normalised distance lags, calculated over the measured DEM and the truth DEM, in both the flow (black lines) and the transverse (grey lines) direction. A threshold of 0.01 was used to remove the influence of slopes smaller than the threshold, which are considered not reliable.

inclination index with increasing separation. Whilst this condition may be fulfilled in the flow direction, Millane et al. (2006) also suggest that suitable conditions are only met when the peak value of the inclination index is larger than 0.05 , which is not the case for our DEM data (Fig. 6). Thus the ability of the surface represented in the ground truth model to assess the external reliability of the measurements, based on the inclination index, is not ascertained. A surface, presenting a clear imbrication of gravels, would in theory be more suitable.

\section{DISCUSSION}

\section{$7.13 D$ printed ground truth for DEM quality assessment}

The study presented is, to the authors' knowledge, the first where $3 \mathrm{D}$ printing is utilised to provide a ground truth object for DEM quality assessment. 3D printing is a fast-growing technology, which is available in most fabrication laboratories. Although future developments will improve the fabrication process and the ability to produce various ground truth objects, this study showed that 3D printing is already mature enough to improve substantially on previous approaches for DEM quality assessment. Previous studies are characterised by the need of an additional instrument, which is affected by measurement errors, to locate and register check points within the DEM. Additionally, the preparation of ground truth data is repeated for each assessment and requires DEM reconstruction and error editing, which is time consuming. This is replaced by the preparation of a reliable and practical 3D printed model. A 3D printed model provides a dense and accurate set of check data, from which reference values for some external parameters can be extracted. In addition, the depth accuracy with which the 3D model was printed, between 0.033 and $0.066-\mathrm{mm}$, and no error slip, ensures increased confidence in check point location.

The size of the 3D printed model, $296 \times 184-$ $\mathrm{mm}^{2}$, which is the maximum size the $3 \mathrm{D}$ printer available for the study allowed, might not be suitable for all applications. Current solutions for DEM quality assessment over larger measurement windows are (i) to move the ground truth to determine the spatial distribution of DEM errors, or (ii) to produce several ground truth models that can be merged.

The inherent difficulty related to the use of a 3D printed model to assess surface errors is the need to produce a realistic model of the surface to survey, since a global measure of error can be unreliable if it is based upon test sites that have little resemblance with the site of interest (Wang et al., 2009, Lane et al., 2005). Topography has an essential impact on measurement quality, especially with photogrammetric surveys, with occluded regions accounting for most of the errors detected on the surface (Chandler et al., 2001). A realistic topography was acquired by measuring a patch of gravel bed, representative of simulated riverbeds in laboratory flumes. However, because the ground truth was acquired with imagery, the topography of the resulting printed model is also missing some details at the interstices between particles, which are not always able to be measured accurately with imagery. A technique, which allows vertical recording, such as laser scanning, if available, may theoretically improve the details at the interstices between particles of the ground truth.

\subsection{Performance of photogrammetry}

The assessment showed that very high accuracy was achieved with digital stereo photogrammetry (Table III). The actual measurement accuracy, represented by a MUE of $0.43-\mathrm{mm}$ and SDE of $0.62-\mathrm{mm}$, was not severely degraded compared with the theoretical vertical precision, $0.39-\mathrm{mm}$, afforded by the setup (Table II). Figure 4 showed that the loss in precision is associated with occlusions in the imagery, suggesting that the process steps undertaken to reconstruct the DEM were correctly executed, with minimal error propagation.

The evaluation of DEM external reliability was complementary to the assessment of DEM accuracy. An increased skewness and reduced standard deviation of bed elevation, compared with the "true" values, confirmed that most errors are found in negative elevations, thus at the gaps between particles. The semivariogram approach showed larger horizontal structures for the measured DEM. It was hypothesised that the smoothing of areas occluded in the imagery may also be responsible for this effect. The use of the inclination index as a parameter for external reliability assessment failed at providing new insights. A possible reason is the detail with which 
gravel imbrications are presented in the $3 \mathrm{D}$ printed model.

\section{CONCLUSION}

This paper has outlined the elaboration of a novel technique for DEM quality and roughness assessment, based on advances in 3D printing technology. As has been shown, this strategy over performs the previous works with respect to the (i) density and repartition of check points; (ii) confidence in check point estimation and registration with the DEM; and (iii) applicability and versatility of the method.

Present approach limitations relate to a relatively small size of the printed 3D model. Fast development of 3D printing technology may soon allow for much larger models of resolution/accuracy, being similar to the present one, and solutions for assessing the larger DEMs were proposed.

Although the statistical accuracy/precision of the survey was high (MUE of $0.43-\mathrm{mm}$ and SDE of 0.62-mm), our assessment confirmed that occlusions are a principal source of the DEM errors, especially at edges and gaps between gravel particles. Ultimately, the use of 3D printed gravel beds will allow for investigating ways to reduce the effect of occlusions and defining the most suitable strategy for gravel-bed DEM collection, both in air and through water.

\section{REFERENCE}

Aberle, J. \& Nikora, V. 2006. Statistical properties of armored gravel bed surfaces. Water Resources Research, 42, W11414.

Andreas, E. L. \& Trevino, G. 1997. Using wavelets to detect trends. J. Atmos. Oceanic Technol. (JTECH), 14, 554564.

Bertin, S. \& Friedrich, H. 2014. Measurement of gravel-bed topography: an evaluation study applying statistical roughness analysis. Journal of Hydraulic Engineering, In Press.

Bertin, S., Friedrich, H., Delmas, P. \& Chan, E. 2013. The Use of Close-Range Digital Stereo-Photogrammetry to Measure Gravel-Bed Topography in a Laboratory Environment. In: 35th IAHR Congress, 2013 Chengdu, China.

Bouratsis, P., Diplas, P., Dancey, C. L. \& Apsilidis, N. 2013. High-resolution 3-D monitoring of evolving sediment beds. Water Resources Research, 49, 977-992.

Butler, J. B., Lane, S. N. \& Chandler, J. H. 1998. Assessment of DEM Quality for Characterizing Surface Roughness Using Close Range Digital Photogrammetry. Photogrammetric Record, 16, 271291.

Butler, J. B., Lane, S. N. \& Chandler, J. H. 2001. Characterization of the structure of river-bed gravels using two-dimensional fractal analysis. Mathematical Geology, 33, 301-330.

Butler, J. B., Lane, S. N., Chandler, J. H. \& Porfiri, E. 2002. Through-Water Close Range Digital Photogrammetry in Flume and Field Environments. Photogrammetric Record, 17, 419-439.

Carbonneau, P. E., Lane, S. N. \& Bergeron, N. E. 2003. Costeffective non-metric close-range digital photogrammetry and its application to a study of coarse gravel river beds. International Journal of Remote Sensing, 24, 2837-2854.

Chandler, J., Fryer, J. \& Jack, A. 2005. Metric capabilities of low-cost digital cameras for close range surface measurement. Photogrammetric Record, 20, 12-26.

Chandler, J., Shiono, K., Rameshwaran, P. \& Lane, S. 2001. Measuring Flume Surfaces For Hydraulics Research Using a Kodak DCS460. Photogrammetric Record, 17(97), 39-61.

Detert, M. \& Weitbrecht, V. Year. Automatic object detection to analyze the geometry of gravel grains. In: (Ed.), M., ed. River Flow 2012, 2012 San Jose, Costa Rica. San Jose, Costa Rica: Taylor and Francis Group, 595600.

Hodge, R., Brasington, J. \& Richards, K. 2009. Analysing laser scanned digital terrain models of gravel bed surfaces: linking morphology to sediment transport processes and hydraulics. Sedimentology, 56, 2024-2043.

James, T. D., Carbonneau, P. E. \& Lane, S. N. 2007. Investigating the effects of DEM error in scaling analysis. Photogrammetric Engineering and Remote Sensing, 73, 67-78.

Lane, S. N., James, T. D. \& Crowell, M. D. 2000. Application of Digital Photogrammetry to Complex Topography for Geomorphological Research. Photogrammetric Record, 16, 793-821.

Lane, S. N., Reid, S. C., Westaway, R. M. \& Hicks, D. M. 2005. Remotely Sensed Topographic Data for River Channel Research: The Identification, Explanation and Management of Error. Spatial Modelling of the Terrestrial Environment. John Wiley \& Sons, Ltd.

Mao, L., Cooper, J. R. \& Frostick, L. E. 2011. Grain size and topographical differences between static and mobile armour layers. Earth Surface Processes and Landforms, 36, 1321-1334.

Millane, R. P., Weir, M. I. \& Smart, G. M. 2006. Automated Analysis of Imbrication and Flow Direction in Alluvial Sediments Using Laser-Scan Data. Journal of Sedimentary Research, 76, 1049-1055.

Nikora, V. I., Goring, D. G. \& Biggs, B. J. F. 1998. On gravelbed roughness characterization. Water Resources Research, 34, 517-527.

Qin, J., Zhong, D., Wang, G. \& Ng, S. L. 2012. On characterization of the imbrication of armored gravel surfaces. Geomorphology, 159-160, 116-124.

Robert, A. 1988. Statistical properties of sediment bed profiles in alluvial channels. Mathematical Geology, 20, 205225.

Smart, G., Aberle, J., Duncan, M. \& Walsh, J. 2004. Measurement and analysis of alluvial bed roughness. Journal of Hydraulic Research, 42, 227-237.

Smart, G., Duncan, M. \& Walsh, J. 2002. Relatively Rough Flow Resistance Equations. Journal of Hydraulic Engineering, 128, 568-578.

Wang, C.-C., Hefner, B. T. \& Tang, D. 2009. Evaluation of Laser Scanning and Stereo Photography Roughness Measurement Systems Using a Realistic Model Seabed Surface. IEEE Journal of Oceanic Engineering, 34, 466-475. 